\title{
Implementing a Health Research Communication Program in a Low Resource Country: Experience from Uganda's Makerere University School of Public Health
}

Scholarly and Research

Communication

VOLUME 4 / ISSUE 2 / 2013

Jennifer Bakyawa

Uganda Virus Research Institute

David Serwadda

Makerere University School of Public Health, Mulago Hospital Complex

Michael Devlin

International Center for Agricultural Research in the Dry Areas (ICARDA)

Carel IJsselmuiden

Council on Health Research for Development

\section{Abstract}

This field note describes the conception, implementation, and results of an 18-month joint health research communication project, which was realized at the Makerere University School of Public Health. The project was one of the first of its kind at the university, in Uganda, and in East Africa. The authors provide an overview of a communication framework that was designed as a result of the project. The framework is intended to inform anyone who is considering an investment in research communication in a low resource institution or country. The project's key themes about research are described: advocacy, media engagement, community and user participation, the influence of research on policy, fundraising, and networking. These themes were synthesized from literature review observations, project interactions and activities, as well as from a situation review post-project. In conclusion, the authors find that research communication in Uganda is still low and ill-coordinated.

\section{Résumé}

Cette note de terrain présente la conception, la mise en œuvre, et les résultats d'un projet conjoint de 18 mois sur la communication dans le domaine de la recherche en santé, réalisé à l'école de santé publique de l'Université de Makerere. Le projet était l'un des premiers du genre à l'université, en Ouganda, et en Afrique de l'Est. Cette note de terrain donne un aperçu du cadre de communication qui a été conçu à la suite du projet. Le cadre vise à informer toute personne qui envisage un investissement dans la

\section{CCSP Press}

Scholarly and Research Communication

Volume 4, Issue 2, Article ID 0205103, 20 pages

Journal URL: www.src-online.ca

Received May 17, 2012, Accepted March 17, 2013, Published November 30, 2013

Bakyawa, Jennifer, Serwadda, David, Devlin, Michael \& IJsselmuiden, Carel. (2013). Implementing a Health Research Communication Program in a Low Resource Country: Experience from Uganda's Makerere University School of Public Health. Scholarly and Research Communication, 4(2): 0205103, 20 pp.

(C) 2013 Jennifer Bakyawa, David Serwadda, Michael Devlin \& Carel IJsselmuiden. This Open Access article is distributed under the terms of the Creative Commons Attribution Non-Commercial License (http://creativecommons.org/licenses/by-nc-nd/2.5/ca), which permits unrestricted non-commercial use, distribution, and reproduction in any medium, provided the original work is properly cited.

Jennifer Bakyawa is a communications consultant who trained as a knowledge manager and journalist and worked as one for more than five years. She has written health stories, including some on research evidence. She has been engaged in different research communication activities such as training journalists on working with researchers, training researchers on working with journalists and summarizing research into briefs for general audiences. She is now a Communications Fellow with the Uganda Virus Research Institute. Email: jfbakyawa@hotmail.com .

Professor Serwadda is an infectious disease epidemiologist. Dr. Serwadda was among the first researchers to report on the presence of AIDS/HIV in Uganda (Lancet, 1984) and has worked continuously on HIV-related research and prevention since the mid1980 s. He has been a senior investigator on the Rakai Program since its inception in 1988. Email: dserwada@infocom.co.ug . 


\section{Scholarly and Research}

\section{Communication}

VOLUME 4 / ISSUE 2 / 2013

Micheal Devlin is an expert

in science and policy

communication and

knowledge sharing. He has

worked in a management role

for several research and

international development

organizations in Brussels, Sri

Lanka, and Geneva. Email:

M.DEVLIN@CGIAR.ORG .

Professor Carel IJsselmuiden

is Director of COHRED and

holds medical and public

health qualifications. He has

published widely in several

areas, and received several

prizes and awards for his work in epidemiology and public

health. He is a senior

executive member of the

Southern African Research

Ethics Training Initiative and

teaches an annual

international research ethics

course at the University of

KwaZulu Natal. Email:

carel@cohred.org. communication de la recherche dans un pays ou une institution à revenus faibles. Cette note de terrain décrit les principaux thèmes du projet sur la recherche : Plaidoyer, participation des médias, participation de la communauté et des utilisateurs, l'influence de la recherche sur la politique, la collecte de fonds et le réseautage. Ces thèmes ont été synthétisés à partir des observations issus de la revue de la littérature, des activités et interactions du projet, ainsi que d'une revue de la situation post-projet. Cette note de terrain conclut que la communication de la recherche en Ouganda est encore faible et mal coordonnée.

\section{Keywords}

Research; Research communication; Fundraising; Networking; Advocacy; Media engagement; Community participation; Policy influence

\section{Introduction}

The need to communicate science has for decades been part of the research debate (Bennett \& Jennings, 2011). Science communication involves several formats such as peer-reviewed journals, workshops or conferences, policy papers and media (Ranson \& Bennett, 2009; Hennink \& Stephenson, 2004).

Of recent, much debate has been stirred regarding the need to improve and expand science communication from traditional communication audiences and formats to other users and structures (Searle, 2012). There has been little support within the science community to encourage peers to communicate to other targeted audiences (Bowater \& Yeoman, 2013).To some researchers, science communication involving other than their peers or policy makers is bother (Searle, 2012). However, science communication is no longer for researchers to decide independently-to whom they communicate and how (Searle, 2012).

Science communication today, involves not only researchers and their participants, but also people who fund the research, communicate it, draft policy for its implementation, researchers in the future, and communities wherein policy is implemented (Court \& Young, 2003; Hovland, 2005; Martin-Sempere, Garzón-García, \& Rey-Rocha, 2008; 2002). Today, any scientist, who desires to thrive, should substitute the traditional approach to science communication with new methods such as engaging with more audiences in an orderly fashion.

\section{Observations from literature review}

Many theories have been proposed to explain why science communication barely succeeds. Whereas there are several theories, this review will focus on three major themes that emerge repeatedly throughout the literature reviewed. These themes are: scientists lacking communication; their failure to link other audiences other than policy makers; and their continued use of traditional communication channels such as journals and conferences to communicate science.

Although the literature presents these themes in a variety of contexts, this literature review will primarily focus on the absence of orderliness in the current research communication with policy makers to whom researchers attempt to send their messages; the need for researchers to include other target audiences and know them; 
and, the necessity for communities where research is conducted to actively demand research that affects them.

Many research institutions intent on using science research and its communication to spur on development still emphasize consulting with policymakers (Kuruvilla \& Maysa, 2005). While this is an important part of the process, a few researchers are also recognizing the value in listening to and understanding the specific communities at whom their research efforts are aimed (Crosswaite \& Curtice, 1994; Miller \& Gregory, 1998).

It has been suggested that the failure of scientists to link meaningfully with the public stems from a lack of communication skills on the part of individual researchers or from a lack of systematic investment in communication by research organizations (Royal Society, 2005). Yet researchers need to be clear about what audiences they are trying to influence with their work. It is essential that researchers communicate with and give feedback to the communities to whom their research is relevant (Mueller, McBride, Coburn, Slifkin, Wakefield, \& Mackinney, 2007; Research Matters, 2008). Communities, too, should demand that researchers conduct research that is central to their needs. Civic organizations can ably promote community concerns through advocacy and through dialogues with researchers and decision-makers on community health issues.

Lamentably, in Uganda, there are no regular meetings of researchers and policymakers to turn research findings into policy. Hence policymakers and other research users, such as specialized communicators, rarely demand scientific information (Ministry of Health, 2010/2011-2014/2015). While research is regarded as a contributing factor to Uganda's development (Ministry of Health, 2010/2011-2014/2015), its recognized value is not matched with a commensurate level of funding (COHRED, 2008). The lack of clear budgets for research in health inevitably makes dissemination a costly activity, even when it involves few people (Royal Society, 2005).

Like in other developing countries, researchers in Uganda still employ traditional communication methods, such as scientific publications and presentations at conferences, workshops, and seminars, to disseminate research (Hennink \& Stephenson, 2004; IJsselmuiden, de Haan, \& Kennedy, 2005-2006; Ranson \& Bennett, 2009). However, these traditional avenues are not normally accessible to the majority of Ugandan research users (Lang, 2003). Research users in Uganda include policymakers, communicators, urban and rural poor, researchers, students, civil society and donors.

Foreign journals are costly, use a foreign language, and their delivery methods, such as the Internet, are not readily accessible to many Ugandan communities. According to the International Federation of Library Associations and Institutions, by September 2006 , only $1.7 \%$ of over 24 million people in Uganda were accessing the Internet (International Federation of Library Associations and Institutions/Committee on Freedom of Access to Information and Freedom of Expression, 2007). 


\section{Scholarly and Research}

\section{Communication}

VOLUME 4 / ISSUE 2 / 2013

\section{Rationale for research communication}

Good policy tends to emerge from good policymaking - and good policymaking involves listening and engaging with the people interested in or affected by an issue (Court \& Young, 2003). It is essential for researchers to plan for communication throughout the research process (Department for International Development, 20082013) because it is important to the success of research programs (Hovland, 2005).

According to Hovland (2005), the communication of evidence, information, and knowledge is undertaken in order to inspire and inform development policy and practice. Communication, when done well, benefits both the recipient and the sender of the message. However, the sender of the information must make efforts to actively engage with the receiver using targeted and meaningful communication channels, if the latter is to regard the research evidence as credible and useful.

Research groups involved in research, either directly or indirectly, play a role in research communication (Martin-Sempere, Garzón-García, \& Rey-Rocha, 2008). These groups can, for instance, invest in science communication directly or engage in a dialogue with different research users (Figueroa, Baris, Chandiwana, \& Kvaale, 2002). The more that researchers engage and communicate with each group in a meaningful way, the more likely the groups will learn how to maximize the uptake and impact of the research (Hovland, 2005). Active participation in research user groups helps to guarantee access to early results and provides opportunities for policymakers to ensure that research provides the most useful evidence (Court \& Young, 2003).

Nevertheless, science communication should be planned and carried out by specialized communicators (Rose, 2003), as discussed later in this field note.

\section{Benefits of health research communication}

Dissemination of research findings to policy-makers, communicators, communities, and other researchers is very important (Ministry of Health, 2010/2011-2014/2015). Research provides background data and empirical generalizations from which policy ideas and choices are derived (Hailey, 2008; Haines, Kuruvilla, \& Borchert, 2004; Lavis, Davies, Oxman, Denis, Golden-Biddle, \& Ferlie, 2005; World Health Organization, 2004).

Additionally, the sharing of knowledge helps in the co-ordination of research and the avoidance of costly and time-consuming duplication (Davies \& Bressan, 2010; Pakenham-Walsh, 2003). Information dissemination and networking are important strategies within the Essential National Health Research (ENHR) mechanism (Figueroa, Baris, Chandiwana, \& Kvaale, 2002; Global Health Watch, 2005).

Networking is a vital part of health research communication, but it is rare in Uganda and Africa as a whole (Bakyawa, 2008). Networking enables researchers to lend their unique expertise to job identification, the design and execution of the study to postresearch activities such as incorporating research consequences into policy. Networking can result in the creation of online/Internet and independent think tanks, to which ministries of health and authorities can turn for thoughts on and solutions to public wellness.

Bakyawa, Jennifer, Serwadda, David, Devlin, Michael \& IJsselmuiden, Carel. (2013). Research communication program in Uganda. Scholarly and Research Communication, 4(2): 0205103, 20 pp. 
Networking is also important in reducing isolation of researchers, providing a fertile environment for the creation of synergies amongst researchers and research issues (Davies \& Bressan, 2010). Without networking, it is hard for newer research workers to make a name for themselves, and clear avenues for advancement become difficult to find, which is a source of frustration.

\section{Description of the research communication project}

Between 2006 and 2007, the Council on Health Research for Development (COHRED) and the Makerere University School of Public Health (MakSPH or the School) jointly piloted an 18-month health research communication project. The project aimed to better understand what needs and challenges health research institutes in developing countries currently face in regards to research communication.

This was a learning project that analyzed the research communication capabilities, limitations, and realities of MakSPH itself. Learnings from this project are useful and can then be applied to the work of other research groups.

MakSPH is one of the schools that constitute the Makerere University College of Health Sciences. The other schools are: School of Biomedical Sciences, School of Health Sciences, and School of Medicine. MakSPH's history dates back to 1957 when the Department of Preventive Medicine was established at Makerere University Medical School. In 1975, the department was elevated to Makerere Institute of Public Health and later to School of Public Health. It became a constituent school of the Makerere University College of Health Sciences in 2007. MakSPH has for years been one of the leading institutions in public health research in Uganda. MakSPH was selected for the collaboration because the institution has produced several researches independently or with partners that have contributed to national health policy and global health guidelines. Despite this there were still no clear procedures for research communication.

A Ugandan project leader was attached to MakSPH to facilitate the process, which was guided by a cross-departmental advisory group at the School. Two COHRED staff based in Geneva, Switzerland, also formed part of the team. They gave technical input and occasionally participated in the project activities.

Two external expert consultations informed the thinking of the project. A meeting with an international group on science communication - of health policy-makers, members of the media, researchers, and members of civil society - was held at the Human Resources for Health Research conference in Nairobi, Kenya, in July 2006. In November 2006, another expert group for the COHRED special session on research communication was held during the Global Forum for Health Research meeting in Cairo, Egypt.

In addition, senior staff members of seven health research institutions in Africa were contacted informally to gain an understanding of their ongoing communication activities. The institutions were: Centre d'Etudes sur les Ressources Végétales (CERVE) and Centre National de Recherche et de Formation sur le Paludisme (CNRFP) from West Africa; MakSPH, Makerere University Faculty of Medicine, and the Infectious 


\section{Scholarly and Research}

\section{Communication}

VOLUME 4 / ISSUE 2 / 2013
Diseases Institute in Uganda; Ifakara in Tanzania; and Kenya Medical Research Institute from East Africa.

The project leader held several internal and external consultations with journalists, policymakers in Ministry of Health $(\mathrm{MOH})$, senior Makerere University researchers, an impoverished slum community typically chosen by public health researchers for research, civil society, and donors. The consultations were intended to inform research actors, to gather their input on health research and its related communication needs in Uganda, and to understand better how those research actors could actively participate in the MakSPH's research process.

At the inception of the project, the project leader made an introductory presentation describing its purpose and strategies for its implementation to MakSPH's management. The leader formed a representative advisory group from four of five departments of MakSPH who participated actively. The departments were: Community Health and Behavioral Sciences, Health Policy, Planning and Management, Disease Control and Environmental Health, and Epidemiology and Biostatistics. The Health Policy Planning and Management department head chaired the five-person advisory group and acted as the Ugandan co-supervisor. The advisory group met several times and exchanged emails on how the School communicated research internally and externally. Key informant interviews were performed with senior MakSPH staff, such as research program leaders, the Dean and his deputy, department heads, and researchers. One meeting, respectively, was held with the Community Health and Behavioral Science and Health Policy Planning and Management departments to discuss: better information management, linking well with research users, and generating information products that best inform and influence potential research users.

Focus group discussions were held with slum dwellers to better understand how research users could be better linked to the School's research process. A number of consultations with MakSPH stakeholders were held to inform MakSPH staff and gather the stakeholders' input on health research and its related communication needs in Uganda.

Stakeholders were purposely sampled and consulted on shaping the MakSPH's research communication. They included journalists who repeatedly report on health issues, researchers, members of an urban impoverished community where researchers and students would typically select study participants, a non-government organization (NGO) influential and active in health promotion, health donors, and policymakers.

These stakeholders were intentionally selected after reviewing their role in science communication. These consultations and the literature review described above revealed that research is recognized as an important component of Uganda's health system, as is stipulated in the country's Health Sector Strategic Plan (HSSP). Despite this, there is little comprehension of the impact that research can have on solving the country's health problems, and the research effort on the whole is poorly organized (COHRED, 2008). 


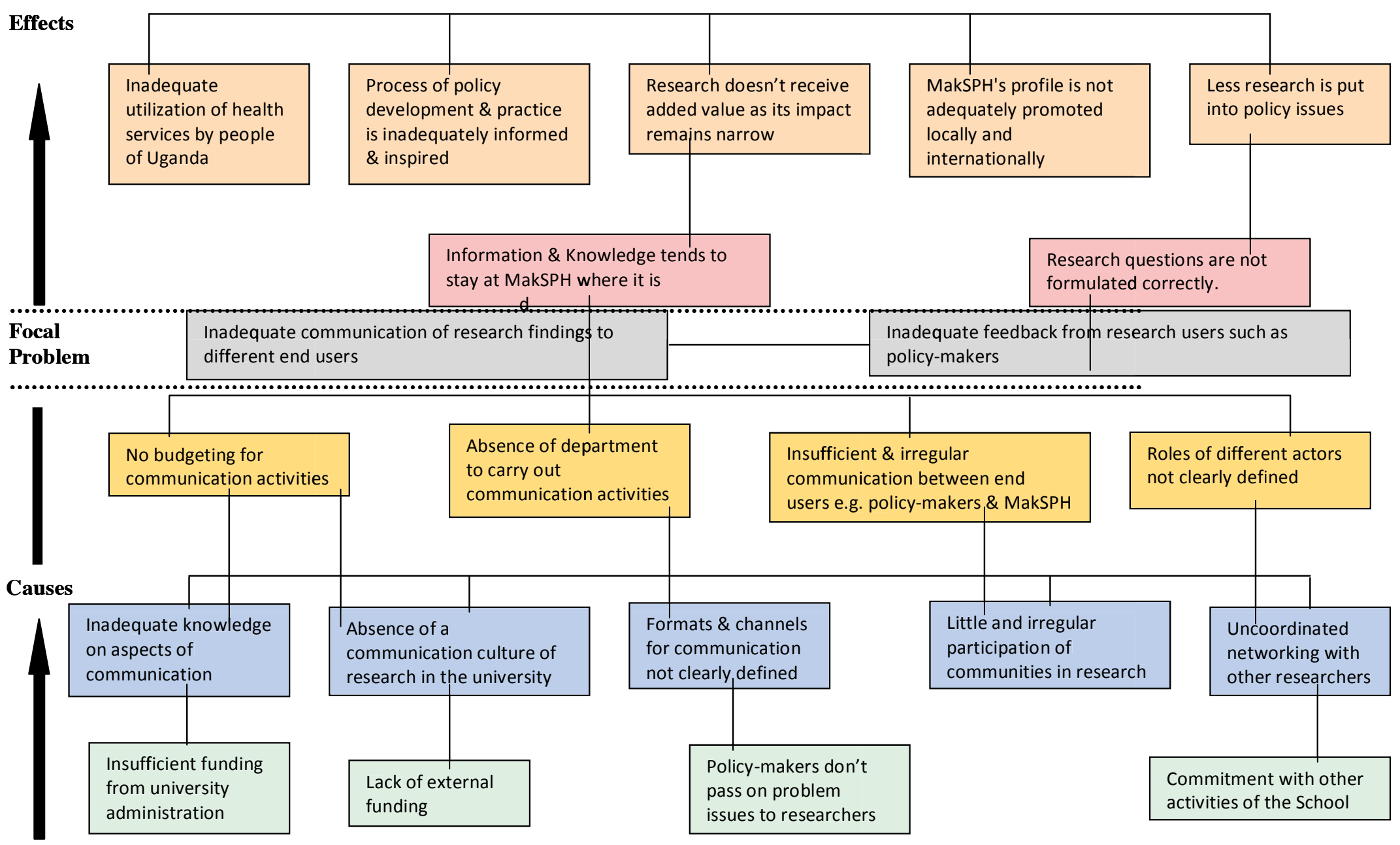




\section{Scholarly and Research}

\section{Communication}

VOLUME 4 / ISSUE 2 / 2013

\section{Analyzing the research communication problem at MakSPH}

A problem tree analysis was prepared to understand better the key areas in which MakSPH needed to improve in research communication. Details of the problem tree analysis are indicated in Figure 1.

The project leader categorized MakSPH target audiences into healthcare funders, policymakers, communicators, educational institutions, United Nations organizations operating in Uganda, regional and international NGOs involved in healthcare. Other categories of target audiences included; research user communities, research institutions and fellow researchers and reviewed the categories with the advisory group.

The advisory group did not respond well to the categorization process and it was substituted with a grid in anticipation that the group would be slowly introduced to drafting a communication framework. The grid included topics such as: identifying messages they wanted to be communicated after completing research that would be undertaken in the future, target audiences, the media/channels they intended to use in order to reach these audiences, and the outcomes they expected from these efforts. Few members replied to emails sent to them. The grid approach was then augmented with the mapping of stakeholders.

A COHRED-developed tool for mapping and analysis of the national health research system was used to generate two maps of all actors in health research, one for Uganda and one for the School. The group was responsive in emails and made suggestions - for instance, on which extra audiences could be included. This approach produced better results.

The group, senior MakSPH and Faculty of Medicine staff, and MOH officials were consulted about stakeholders' communication needs for the School in individual interviews. A format for research briefings and summaries was prepared and discussed with the group.

The following issues that could be addressed arose from the discussions:

- Identifying needs and easier ways of communicating research internally within the School; simplifying study findings; and giving feedback to communities in which the research was conducted. The feedback could include regular updates on the progress of the research and, when completed, what its findings were.

- Methods of better information management and research knowledge in the School, such as writing effective summaries and briefs and sharing research findings consistently and regularly.

- Involving communities in research so that a user perspective can influence and inform the research agenda.

- Engaging the media to highlight the importance of health research to better health and development.

- Communicate research findings effectively to policymakers. 
Based on discussions, comments, and suggestions from the focus groups, departmental meetings, and key informant interviews, we compiled a draft communication framework for the School. Data collected from the mapping process was included in the framework and distributed for review to the advisory group, department heads, and other School and Faculty of Medicine senior staff.

What follows is an overview of the communication framework. It highlights six key themes that emerged from the MakSPH-COHRED collaboration and also what the School's stakeholders considered as pertinent to the success of research communication. Observations and recommendations are given for each key theme. This field note also gives an overview of relevant strategies and targets within the research communication framework. The key themes may be implemented singularly or as a package, but preferably within the confines of a research communication framework or a developed research communication strategy.

\section{Overview of the research communication framework}

The end result of the consultative collaboration was a communication framework (see Table 1) for health research.

The objectives of the framework and proposals for achieving focused research communication were developed by the project leader and the advisory group. The communication framework provides a broader action plan and specific strategies that the School can employ to harness its communication activities within the School and with partner organizations.

The framework recommends that a research organization adopt a research process that includes dialogue with key research users and beneficiaries as a core research activity. This, however, has implications for staffing and investment in communication skills. It calls for new thinking by researchers and management about how research programs and projects can be organized to focus on specific user needs. An institution that invests in this venture would benefit from increased visibility and research relevance and quality.

\section{Key themes from the collaboration}

The advisory group and the team leader identified the following as areas where MakSPH was weak and marked them for collaboration with its stakeholders.

\section{ADVOCACY FOR RESEARCH}

Staff at MakSPH and stakeholders identified advocacy for research as one of the main areas to which the School and other research actors need to attend. Research is an important element of Uganda's health system. This is clearly specified in the country's HSSP of 2010/11-2014/15 (Ministry of Health 2010/11-2014/15). The relevance of research to solving the country's health problems is yet to be understood, even by policy makers. In addition, there is no organization in the country (COHRED, 2008).

Attempts by the Ministry of Health (MOH) to implement advocacy for research over the years were not successful. An $\mathrm{MOH}$ working group on health research with a 
Scholarly and Research Communication

VOLUME 4 / ISSUE 2 / 2013
Table 1: Summary of the communication framework indicating proposed strategy and execution

\begin{tabular}{|c|c|}
\hline Strategy & Proposed Approach \\
\hline $\begin{array}{l}\text { Defining } \\
\text { communication } \\
\text { roles in research } \\
\text { organization }\end{array}$ & $\begin{array}{l}\text { - Director provides political backing and funds for communication within } \\
\text { the organization. } \\
\text { - Head of Department, Program/ Project Leader ensures that a } \\
\text { communication focus is integrated into the research program. } \\
\text { - Researcher works with the communication specialist to identify and } \\
\text { include potential users of the research in the project planning and } \\
\text { implementation. } \\
\text { - Communicator packages research information products and manages } \\
\text { various practical information products that will ensure the organization is } \\
\text { better known. }\end{array}$ \\
\hline $\begin{array}{l}\text { Establishing a } \\
\text { research cycle } \\
\text { that engages an } \\
\text { organization's } \\
\text { research with its } \\
\text { key stakeholders } \\
\text { and users }\end{array}$ & $\begin{array}{l}\text { - Involving communities and research beneficiaries through encouraging } \\
\text { program leaders to develop a plan as part of the research strategy. } \\
\text { - Building dialogue with policymakers on pertinent issues and on how the } \\
\text { research organization can provide evidence to support their decisions. } \\
\text { - Building relationships with the media. } \\
\text { - Supporting the region/country's crisis management for disease and } \\
\text { medical crises. } \\
\text { - Organizing institutional information; knowledge management. }\end{array}$ \\
\hline $\begin{array}{l}\text { Putting research } \\
\text { communication } \\
\text { into action at } \\
\text { research } \\
\text { organization } \\
\text { (skills needed) }\end{array}$ & $\begin{array}{l}\text { - Communication and knowledge sharing specialist. } \\
\text { - Writer/Editor. } \\
\text { - Documentalist/Information Manager. } \\
\text { - Health policy analyst. }\end{array}$ \\
\hline $\begin{array}{l}\text { Proposed } \\
\text { activities and } \\
\text { outcomes }\end{array}$ & $\begin{array}{l}\text { In } 3 \text { years After internal and external consultations with different } \\
\text { stakeholders, the research organization establishes a research communication } \\
\text { unit } \\
\text { Proposed Year } 1 \text { targets } \\
\text { - Defined communications roles included in organization strategic } \\
\text { operational plan. } \\
\text { - Budget allocated for some new activities and services. } \\
\text { - Heads of Departments identify key communities and user groups who can } \\
\text { benefit from their research. } \\
\text { - 2-3 high-level roundtables planned with national policy/decision-makers. } \\
\text { - Organization's head agrees to a plan of media briefings; at least one department } \\
\text { agrees to engage with media as a part of its yearly work plan. } \\
\text { - The organization defines how it can uniquely contribute to solving national } \\
\text { health crises and developing an action plan. } \\
\text { - Process defined for creating summaries for each project. }\end{array}$ \\
\hline
\end{tabular}

mandate to ensure that health research is part of the country's health activities was not very active (MakSPH, 2006-2007).

A survey done in 2000 by the Uganda National Health Research Organization (UNHRO) concludes that the limited availability of resources for research has led many institutions in the country to view research as an add-on and not a main activity. The analysis states that a reasonable number of researchers who conduct health research in several institutions exist, but only a few of these organizations such as the Uganda Virus Research Institute (UVRI) and Trypanasomiasis Research in the Livestock Health Research Institute (LIRI) are devoted to health research alone. Most of the other institutions carrying out health research are university institutions, which communication program in Uganda. Scholarly and Research Communication, 4(2): 0205103, 20 pp. 
are mainly devoted to teaching. However, whereas health research has been in the country for decades, the UNHRO bill was only passed in 2009 and gazetted by the Government of Uganda in 2011. UNHRO is yet to receive ample independent funding from government to enable it to execute its mandate.

For years, UNHRO's lack of a legal status crippled its capacity to actively steer research activities in the country, such as priority-setting and research communication. Often this research was not policy-oriented and the priority-setting and research communication was uncoordinated (Ministry of Health, 2010/11-2014/15).

Observation: Whereas most of the School's stakeholders expressed an interest in engaging with researchers, they were rarely proactive. Researchers were not interested in becoming research communication advocates. Advocacy for research should not be left to researchers engaged in specialized research activities, but done in conjunction with partners who concentrate on this activity solely.

We recommend that research organizations build partnerships to advocate for inclusion of research on the national agenda, integration of communication in the country's health research system, and recognition of the role of research as a contributor to national development.

\section{Media ENGAGEMENT}

The journalism profession in Uganda is still young (Ochilo, 2005). More than 20 years after the first journalism education curriculum was introduced in the country (Ochilo, 2005), no education institution to date offers specialized health reporting (Ochilo, 2005). Journalists who report on health take the initiative individually (MakSPH, 2006-2007).

With no formal tutoring, health reporting journalism on research issues in Uganda is a bigger challenge. Journalists in Uganda keep away from reporting on research since they deem it complicated and unattractive (MakSPH, 2006-2007). Formats and avenues that scientists use to present their results, such as journals, conferences, and jargon-laden reports, do not make it easy for journalists.

On several occasions, journalists have accused scientists of withholding information from them - information they perceive that the public has a right to know (MakSPH, 2006-2007). Scientists, too, are weary of working with the media lest their information be misinterpreted and misrepresented (MakSPH, 2006-2007). Researchers have conceded that the media is a powerful ally that public health professionals are not utilizing fully (Research Matters, 2008). Some MakSPH researchers, though, have tried to connect with the media by appearing on radio and television programs to discuss research (MakSPH, 2006-2007).

Journalists feel that constant interaction between the media and researchers will help reduce suspicion on both sides - for instance, through regular monthly press briefings where topical issues are discussed. They want interesting research findings to be synthesized into simple formats such as press releases (MakSPH, 2006-2007). 


\section{Scholarly and Research}

\section{Communication}

VOLUME 4 / ISSUE 2 / 2013
Observation: Researchers, media, and communities are trying to connect with each other, but these efforts are ill-coordinated. Researchers lack the expertise required to market and communicate findings and yearn to understand how the different parties receive and pass on information to each other. They feel that though communication specialists know best how to communicate research issues, the communication should be done in partnership with them.

We recommend that research institutions hire a communication specialist to synthesize findings for different user groups as an avenue to bridge the gap between scientists and the public. Where there is no formal training in health reporting in a country, an institution should liaise with a journalism school to help fill this void.

\section{COMMUNITY AND USER PARTICIPATION IN RESEARCH}

All seven organizations consulted at the beginning of the project revealed that research communication and dissemination of findings is generally inadequate, irregular, and poorly coordinated (MakSPH, 2006-2007.) MakSPH and the Faculty of Medicine researchers believe that for many people in Uganda, research still remains a mystery.

Whereas researchers conduct research, they rarely interact with users of their information (Ministry of Health, 2010/11-2014/15). Few, if any, research organizations have research communication strategies that take account of their various stakeholders, particularly the communities where their research data is collected (MakSPH 2006-2007).

During the project's implementation, there was no research department or any one person designated to undertake research activities at Makerere University. Apart from students' theses, research that was conducted at the School was often sourced through external collaborations within and outside the country. There were attempts to involve communities in research in addition to data collection. The School still runs a demographic surveillance system site in two rural districts and with other university partners.

Communicating research findings in conferences, journals, and other traditional formats is initiated by individuals and not by organizations. Some organizations hold journal clubs for different departments (MakSPH, 2006-2007).

The management of only one of the seven organizations consulted (the CNRFP from West Africa) had deliberately attempted to link communities and research users by building a communications component into some projects. Most researchers worked with communities. However, the interaction with communities was typically during research planning and at the feedback stage. No specified activity prepared communities to provide input into the programs or absorb results of the work. The CNRFP had tasked an employee with communications and a plan to prepare its newsletter. However, this project folded due to challenges of organizing information and getting researchers to submit their information.

The community members contacted longed for researchers to return with project feedback in the form of seminars and workshops and discussions about the implications of the research results for them. They desired to be involved in research 
activities, such as collecting information about numbers of births, deaths, illnesses, and treatments given in their community on an ongoing basis.

Communities wanted their parliamentary and local council representatives to link their research needs to government. Communities expressed a desire that researchers live within the community for some months while a given study is conducted. This would enable the researchers to better understand the research issues and to feel a sense of obligation to return to the community to give it feedback, and, in general, it would make their work easier.

Researchers could appoint community coordinators to iron out suspicions about researchers who conduct research haphazardly in a bid to save funding.

Observation: Community members can be active participants in health research apart from data collection. If properly prepared, they can support researchers by lobbying for change. Institutional websites were not actively used as an avenue for communicating research to different communities. The websites were for description of organizational activities. Any attempts to include research on the websites were replications of scientific publications or annual reports. Whereas many Ugandans cannot access the Internet today, several NGOs and civil society organizations have the ability to access the Internet and pass on the pertinent information to relevant audiences with whom they work. Not atypical to Uganda, little attention was paid to relaying research to different end users in a friendly manner (McGrath, Lawrence, \& Richardson, 2004). Few, if any, research institutions had outreach programs that provided for feedback to communities (Ministry of Health, 2010/11-2014/15; UNHRO, 2000).

We recommend that researchers engage with communities and other potential users of study results as a part of the research process. The users need to be identified explicitly by research program leaders and communications specialists at the beginning of the research project.

\section{RESEARCH INFLUENCING POLICY}

In Uganda, UNHRO is mandated to coordinate health research. UNHRO was inactive during the implementation of the project. Lack of legal status of UNHRO gave research institutions liberty to set research priorities and communicate findings without its approval and in an uncoordinated manner (COHRED, 2008). They often conducted research that was neither policy-oriented (COHRED 2008) nor followed priority-setting.

The communication and feedback link between researchers and policymakers is still very weak (Ministry of Health, 2010/11-2014/15). In the absence of a research policy framework, questions are often formulated with little (if any) input from policymakers (Ministry of Health, 2010/11-2014/15). Whereas useful research results are sometimes available for input into policy in Uganda (Ministry of Health, 2010/11-2014/15), the country has few professionals who can package this research in easily digestible formats for decision-makers (MakSPH, 2006-2007). 


\section{Scholarly and Research}

\section{Communication}

VOLUME 4 / ISSUE 2 / 2013
At MakSPH, health research is conducted annually, but it is not necessarily linked to policy needs (Ministry of Health, 2010/11-2014/15). Each department continues to initiate and independently run research dissemination activities geared towards policymakers (MakSPH 2006-2007). Researchers organize national seminars tailored to a research program and target donors and health policy-implementing ministries (MakSPH, 2006-2007). Occasionally, the School's staff utilized the MOH's annual review meetings (MakSPH, 2006-2007), but these meetings were only useful to MakSPH staff members to give evidence to ministry officials, if the research was topical.

In the past, public health concerns have arisen and the School did not provide research evidence. The policymakers expect the School to actively make its topical research evidence available to support the $\mathrm{MOH}$ in the event of public health crises and to recommend the way forward. Other interactions between the $\mathrm{MOH}$ and research institutes during the year were often informal, but policy planners valued these meetings and believed that both parties would benefit more if a better structured process or mechanism for dialoguing on health issues and research needs was designed.

At the time of the project's implementation, there was no regular, structured national priority-setting process. The policy planners thus recommended that the School regularly liaise with ministries of health, agriculture, finance, and gender, and local government to identify research priorities that may inform policy issues during seminars held at the beginning and end of major research activities. These alliances would help researchers brief policymakers on what they intend to investigate so that the latter can have input and anticipate findings. Building such relationships with decision-makers would increase research uptake.

Observation: Whereas there are no clear-cut budgets for research and its communication, researchers and program leaders still yearn to understand how different parties receive and pass on information to each other. There are attempts by both policymakers and researchers to bridge the gap between them, but these efforts are weak and ill-coordinated. Because the link between policymakers and researchers is still very weak, research is rarely valued as an entity of policy formulation. When research results are packaged in formats that are easy for decision-makers to access, they can influence policy. Skills for packaging research findings must be provided consciously and constantly for findings to be relevant.

We recommend that research institutions employ communication specialists to train researchers to summarize their findings as a means of making research more accessible internally and externally to fellow researchers, decisionmakers, and donors.

Communication should be incorporated into every research proposal if findings are to be relevant. The $\mathrm{MOH}$ should make health research a central and dynamic part of its policy formulation, planning implementation, and program evaluation.

\section{FUNDRAISING FOR RESEARCH}

Funding of research is part of the Uganda National Council of Science and Technology (UNCST) Statute of 1990. The National Science, Technology and Innovation Policy, 2009 , projected that US $\$ 830 \mathrm{~m}$ was needed as funding for research for five years that were to follow (Ministry of Finance, Planning and Economic Development, 2009). 
However, only in 2007 did a presidential initiative on research (worth US \$50,000) begin. This initiative supports research in areas such as malaria and banana plant diseases. During the same year, the Uganda Government secured a World Bank loan to support research. The Uganda Millennium Science Initiative (MSI) funds senior research teams for up to three years in amounts ranging from US $\$ 500,000$ to $\$ 800,000$. Under the MSI, emerging research teams receive five-year funding in amounts of US $\$ 100,000-\$ 250,000$. Grants of up to US $\$ 50,000$ are available with private sector cooperation (Uganda National Council of Science and Technology website). Since 2007, UNCST has been awarding 12 to 15 grants to researchers in various science fields, including agriculture, engineering, environment, and health. Health researchers are expected to compete with all these sectors for approximately US $\$ 33.35 \mathrm{~m}$ budgeted for two fiscal years (Ministry of Finance, Planning and Economic Development, 2009). The MSI funding expires in June 2013 and there are no clear plans to replenish it.

Research funds in health are generally scarce and several research institutions in Uganda do not have a budget line for research (Ministry of Health, 2010/11-2014/15). In cases where a budget line for research exists, the percentage of the institutional total budget allocated to research is minimal (MakSPH, 2006-2007; COHRED2008). Research communication is a costly activity and is not considered seriously, even by donors (MakSPH, 2006-2007). Often it is a separate and less funded activity. It was found that in cases where a budget needs downsizing, research communication is often the first item that is removed (MakSPH, 2006-2007).

At MakSPH, a clear definition of which constituents the School needs to reach and influence to be successful does exist, but has not been translated from thought to paper. Inevitably, not everyone at the School can disseminate research findings. In some institutions, researchers are allowed to write external funding proposals for their research and extra allowances. Sometimes the institutions assist the researchers compete for these externally funded grants.

On the whole, many institutions have received funding mostly from external sources (IJsselmuiden et al., 2005-2006; COHRED2008), including the donor community, government, and to a lesser extent, local NGOs. The government of Uganda regards research as a contributing factor to development, but does not match this opinion with funding (Ministry of Health, 2010/11-2014/15).

Observation: UNCST estimates suggest that out of the total health research funding in Uganda in 2005/2006, the percentage of health research funds allocated by the Ugandan Government is 5 to $10 \%$ (COHRED, 2008). More effort is required to address the problem of sustained funding for research. There is a need to increase donor support for health research that takes into account community needs and problems. Researchers need incentives to disseminate their findings, and due to shortfalls in income, they are forced to find other avenues to do this. There is no motivation for researchers to take accountability seriously after completing their projects. Increased donor support for health research that takes into account community needs is necessary. It may require new fundraising attention. 


\section{Scholarly and Research}

\section{Communication}

VOLUME 4 / ISSUE 2 / 2013
For effective fundraising for research and research communication, we recommend any of the five following avenues or the whole package:

1. A research organization should follow the guidelines of the United Kingdom (UK) Department for International Development (DFID). The guidelines stipulate that $10 \%$ of all research funded by the DFID should be allocated to specifically-defined communication and knowledge sharing activities to ensure uptake and use of the research after its completion (DFID, 2006). This rule of thumb should be applied to all research funds, where possible, and advocated to all the research organization's donors.

2. Funding through internal sources, where a portion of the budget for each project is allocated to a specific project and the organization's communication activities.

3. Sourcing external funding by writing a proposal seeking funds specifically for improving communications activities at the research organization.

4. Include a communication component in each research project that is specifically prepared to provide funds to the project.

5. Establish a national research fund to allow researchers to investigate more topics on local needs and interact with different groups in society. This national fund would reduce dependency on research that is primarily funded and directed by donors whose interests may not necessarily align with those of the research host.

\section{NETWORKING OF RESEARCHERS}

Attempts to organize research activities in Uganda are just starting. Still, several organizations conduct health research without the knowledge of their counterparts. This disorganization (and the absence of a database) have consequently led to inadequate, irregular, and poor dissemination of research results, a situation that is not only peculiar to Uganda (World Health Organization, 2004). When people exchange research results in the School, it happens out of individual efforts. At the departmental level in the School, researchers update their colleagues during planned or impromptu meetings held to brief them about a presentation scheduled for a later workshop or conference.

Within MakSPH, different departments hold seminars through which research findings are disseminated to staff. The seminar series is also used to brief staff about concept notes, proposals, and what collaborating partners are doing in terms of health research. In the then Faculty of Medicine, Makerere University, and senior leaders believed that networking is necessary and practical in research, especially on issues of shared involvement and concerns.

Where networking of researchers has occurred, as was the case for the male circumcision study in Uganda and Kenya, it has guaranteed maximum use of resources and a speedy answer to the research question. The research question explored the issue of using medical male circumcision as another avenue for preventing the spread of 
HIV/AIDS that affects both countries. This collaboration also provided the opportunity to gain a larger sample size.

Observation: Networking is important in reducing isolation of the researchers and creating new synergies. It is crucial that the private sector be included to encourage additional funding. It is also important to encourage researchers to network at institutional, regional, and international levels to facilitate sharing of experiences and resource maximization. Incentives for researchers to network should also be established.

\section{IMPACTS OF THE RESEARCH COMMUNICATION PROJECT}

The School of Public Health adopted the Communication Framework, and Makerere University College of Health Sciences, in which MakSPH is a constituent, later took it up. A communication specialist was appointed for the School, and later the College also appointed a Communications Officer and a Knowledge Translation Officer. A funding proposal to implement the framework has been written but not yet funded. Several activities at the School are incorporating a communication component, even if it is still at a small scale. Staff members are continuously being co-opted to participate in communication activities such as writing short course curricula on strengthening communication skills for leaders. The College's constituents continue to hold and participate in workshops and seminars on health, health research, and its communication.

\section{Conclusions}

Health research communication has yet to pick up in many low resource countries such as Uganda. It is essential for researchers to plan for communication throughout the research process (DFID, 2008). Research organizations should adopt a research process that includes dialogue with key research users and beneficiaries as a core of their research activity if communication is to develop. However, this approach has staffing implications and requires an investment in communication skills. It calls for new thinking by researchers and management on how research programs and projects can be organized to focus on specific user needs. This investment can greatly increase the relevance, visibility, and overall quality of the research of the School of Public Health.

\section{Recommendations}

Any research group from a low resource institution wishing to adopt this approach should conduct a detailed country situation analysis to identify external stakeholders with whom to work before implementing their project. The establishment of an advisory group is crucial to support the coordinator and give advice on implementation.

For collaborations, it is important that the coordinator work with a focal point person who should continuously assist the organization's staff to understand research translation or science communication, long after the collaboration has ended. 
Scholarly and Research

Communication

VOLUME 4 / ISSUE 2 / 2013

$\begin{array}{ll}\text { Abbreviations } & \\ \text { AIDS } & \text { Acquired Immune Deficiency Syndrome } \\ \text { CIMRC } & \text { Canadian Innovative Materials Research Centre } \\ \text { CERVE } & \text { Centre d'Etudes sur les Ressources Végétales } \\ \text { CNRFP } & \text { Centre National de Recherche et de Formation sur le Paludisme } \\ \text { COHRED } & \text { Council on Health Research for Development } \\ \text { CARE } & \text { Community Alliance for Research and Engagement } \\ \text { DFID } & \text { UK Department for International Development } \\ \text { ENHR } & \text { Essential National Health Research } \\ \text { GOU } & \text { Government of Uganda } \\ \text { INASP } & \text { International Network for the Availability of Science Publications } \\ \text { HSSP } & \text { Health Sector Strategic Plan } \\ \text { HIV } & \text { Human Immunodeficiency Virus } \\ \text { LIRI } & \text { Livestock Health Research Institute } \\ \text { MakSPH } & \text { Makerere University School of Public Health } \\ \text { MSI } & \text { Millennium Science Initiative } \\ \text { MOH } & \text { Ministry of Health } \\ \text { NGO } & \text { Non Governmental Organization } \\ \text { UNHRO } & \text { Uganda National Health Research Organization } \\ \text { UNCST } & \text { Uganda National Council of Science and Technology } \\ \text { UVRI } & \text { Uganda Virus Research Institute } \\ \text { YICB } & \text { Yale Interdisciplinary Center for Bioethics } \\ & \end{array}$

\section{References}

Bakyawa, J. (2007, November 11). Can Africa develop if researchers network? The Monitor. URL: http://allafrica.com/stories/200711100061.html .

Bennett, D.J., \& Jennings, R.C. (2011). Successful science communication: Telling it like it is. Cambridge: Cambridge University Press.

Bowater, L., \& Yeoman, K. (2013). Science Communication: A Practical Guide for Scientists. Oxford: John Wiley \& Sons.

Makerere University School of Public Health. (2006-2007). Information gathered from interviews and consultations in 2006 \& 2007 from management, programme leaders and two departmental focus groups, Dean of Makerere University Medical School; Straight Talk Foundation, Uganda, donors - SIDA, Italian cooperation, GTZ, Japanese cooperation; Ministry of Health - health policy planning department; Uganda National Health Research Organisation.

Council on Health Research for Development (COHRD). (2008). Alignment and harmonization in health research: Uganda country report. URL: http://healthresearchweb.org/files/Uganda_web.pdf [May 12, 2012].

Court, J., \& Young, J. (2003). Bridging research and policy: Insight from 50 Case Studies. Working Paper 213. United Kingdom: Overseas Development Institute.

Crosswaite, C. \& Curtice, L. (1994). Disseminating research results: The challenge of bridging the gap between health research and action. Health Promotion International, 9(4), 289-296.

Davies, H. \& Bressan, B. (2010). A history of international research networking: The people who made it happen, 1st edition, pp. 126-137. Great Britain: Wiley-Blackwell.

Department for International Development. (2006). Lessons learnt on designing communication strategies for research programmes. Workshop report. URL: http://www.dfid.gov.uk/r4d/PDF /Outputs/communication/Lessons_Learnt_Communication_Strategies.pdf [May 11, 2012].

Bakyawa, Jennifer, Serwadda, David, Devlin, Michael \& IJsselmuiden, Carel. (2013). Research communication program in Uganda. Scholarly and Research Communication, 4(2): 0205103, 20 pp. 
Department for International Development. (2008-2013). DFID Research Strategy: Research communication. Working paper series. URL: http://www.research4development.info/PDF/Outputs /Consultation/ResearchStrategyWorkingPaperfinal_communications_P1.pdf [May 9, 2012].

Figueroa, J.P., Baris, E., Chandiwana, S., \& Kvaale, E. (2002). A Survey of essential national health research in nine developing countries. West Indian Medical Journal, 51(2), 97-101.

Global Health Watch. (2005). Holding to account, essential national health research (pp. 341-350). URL: http://www.ghwatch.org/sites/www.ghwatch.org/files/ghw.pdf [May 11, 2012].

Hailey, D. (2008). Effective dissemination of findings from research: A compilation of essays. An overview: Chapter 1. Alberta, Canada: Institute of Health Economics. URL: www.ihe.ca /documents/Dissemination.pdf [May 11, 2012].

Haines, A., Kuruvilla, S., \& Borchert, M. (2004). Bridging the implementation gap between knowledge and action for health: Policy and practice. Theme Papers: Bulletin of the World Health Organisation 82(10), 724-731.

Hennink, M., \& Stephenson, R. (2004). Using research to inform health policy: Barriers and strategies in developing countries, opportunities and choices. Working Paper 9. URL: http://www.socstats.soton .ac.uk/choices/Policymakers\%20WP9.PDF [April 10, 2012].

Hovland, I. (2005). Successful Communication: A toolkit for researchers and civil society organisations. URL: http://www.odi.org.uk/resources/docs/192.pdf [May 15, 2012].

IJsselmuiden, C., de Haan, S., \& Kennedy, A. (2005-2006). The case for national health research: A contribution to global health watch. An alternative world health report. URL: http://www.cohred.org/downloads/open_archive/ArticleCoverFINAL.pdf [May 2, 2012].

International Federation of Library Associations and Institutions/Committee on Freedom of Access to Information and Freedom of Expression. (2007). World Report, 376-378. URL: http://www.ifla .org/faife/report/122\%20IFLA-FAIFE\%202007\%20CR\%20-\%20Uganda.pdf [May 3, 2012].

Kuruvilla, S., \& Maysa, N. (2005). Reorienting health research communication. The Lancet, 366(9495), 1416-1418.

Lang, M. (2003). Communicating academic research findings to IS professionals: An analysis of problems: Informing science. Informing Science, Special series 6, 21-29.

Lavis, J.N., Davies, H.T.O., Oxman, A.D., Denis, J.L., Golden-Biddle, K., \& Ferlie, E. (2005).Towards systematic reviews that inform healthcare management and policymaking. Journal of Health Services Research and Policy, 10(1), 35-48.

Martín-Sempere, M.J., Garzón-García, B. \& Rey-Rocha, J. (2008). Scientists' motivation to communicate science and technology to the public: Surveying participants at the Madrid science fair. Public Understanding of Science, 17(3), 349-367.

McGrath, J.M., Lawrence, V., \& Richardson, W.S. (2004). Making medical research clinically friendly: A communication-based conceptual framework. Education for Health, 17(3), 374-384.

Miller, S., \& Gregory, J. (1998). Science in public: Communication, culture \& credibility. Cambridge, Massachusetts: Perseus Publishing.

Ministry of Finance, Planning and Economic Development. (2009). National Science, Technology and Innovation Policy. URL: http://uncst.go.ug/dmdocuments/STI\%20policy\%20doc\%20march \%202011.pdf [April 30, 2013].

Ministry of Health. (2010). Health sector strategic plan III: 2010/11-2014/15. Kampala, Uganda.

Mueller, K.J., McBride, T.D., Coburn, A.F., Slifkin, R.T., Wakefield, M.K., \& Mackinney, A.C. (2007). Bridging rural health research and policy: Dissemination strategies, rural policy research, institute, rural health panel. URL: http://www.rupri.org/Forms/Health_Panel_Aug07.pdf [May 9, 2012].

Nakajubi, G. (2013, May 1). Science research in balance as World Bank Project ends. The New Vision. URL: http://www.newvision.co.ug/news/642216-science-research-in-balance-as-world-bankproject-ends.html [May 9, 2013].

Bakyawa, Jennifer, Serwadda, David, Devlin, Michael \& IJsselmuiden, Carel. (2013). Research communication program in Uganda. Scholarly and Research Communication, 4(2): 0205103, 20 pp.
Scholarly and Research

Communication

VOLUME 4 / ISSUE 2 / 2013 


\section{Scholarly and Research}

Communication

VOLUME 4 / ISSUE 2 / 2013
Ochilo, P.O. (2005). Communication and journalism curricula in Africa: The case of Kenya, Uganda and Tanzania. Africa Media Review, 11(2), 51-73.

Pakenham-Walsh, N. (2003). Multistakeholder Networking: Lessons learned from the INASP-Health Programme. CIMRC Workshop on Communication of Research Findings - An overview (p. 10). DFID Consultation. URL: www.inasp.info/health [May 10, 2012].

Ranson, M.K., \& Bennett, S.C. (2009). Priority setting and health policy and systems research. Health Research and Policy Systems, 7(27), 1478-4505.

Research Matters. (2008). Knowledge translation toolkit, bridging the 'know do' gap: A resource for researchers. URL: http://www.idrc.ca/EN/Resources/Publications/Pages/IDRCBookDetails.aspx ?PublicationID=851 [March 30, 2012].

Rose, S. (2003). How to (or not to) communicate science. Biochemical Society Award Lecture, Royal Institution. London, Biochemical Society transactions, 31(2). URL: http://www.mendeley.com /research/how-to-or-not-to-communicate-science/ [May 10, 2012].

Royal Society. (2005). Factors affecting science communication: A survey of scientists and engineers. URL: http://royalsociety.org/uploadedFiles/Royal_Society_Content/Influencing_Policy /Themes_and_Projects/Themes/Governance/Final_Report_-_on_website_-_and_amended _by_SK_no_navigation.pdf [May 12, 2012].

Searle, S.D. (2012). Scientists' engagement with the public. In J.K. Gilbert, B.V. Lewensten, \& S.M. Stocklmayer (Eds.), Communication and engagement with science and technology: Issues and dilemmas: A reader in science communication (pp. 41-57). New York, NY: Routledge.

Stocklmayer, S. (2012). Engagement with science: Models of science communication. In J.K. Gilbert, B.V. Lewensten, \& S.M. Stocklmayer (Eds.), Communication and engagement with science and technology: Issues and dilemmas: A reader in science communication (pp. 19-38). New York, NY: Routledge.

Uganda science millennium initiative project. (2007). Uganda National Council of Science and Technology \& Uganda Industrial Research Institute. URL: http://www.uncst.go.ug/dmdocuments /Window\%20C\%20Manual.pdf [January 30, 2012].

World Health Organisation. (2004). World report on knowledge for better health: Strengthening health systems. World Health Report. Geneva, Switzerland: World Health Organization. 